\title{
Microscopy Analysis in CFRP and GFRP Composites Manufactured by LCM and Autoclave Techniques
}

\author{
M. Moreno-Rios ${ }^{1 *}$, J. C. Mendoza Mendoza ${ }^{1}$, E.O. Avila-Davila ${ }^{1}$, E. E. Vera-Cárdenas ${ }^{1}$, S. Ledesma- \\ Ledesma $^{2}$ and A. I. Martínez Pérez ${ }^{3}$ \\ 1. Tecnológico Nacional de México/ITPachuca (DEPI). Col. Venta Prieta, Pachuca de Soto, Hgo., \\ México. \\ 2. Centro de Ingeniería y Desarrollo Industrial (CIDESI), Playa Pie de la cuesta 702, Desarrollo San \\ Pablo, Querétaro, Qro., México \\ 3. Departamento de Ingeniería Mecánica Automotriz, Universidad Politécnica de Pachuca, Carretera \\ Pachuca-Ciudad Sahagún km 20, Ex-Hacienda de Santa Bárbara, Zempoala, Hgo., México. \\ * Corresponding author: moreno_mr@itpachuca.edu.mx
}

Two techniques are used to manufacturing composites of carbon fiber reinforced plastic (CFRP) and glass fiber reinforced plastic (GFRP): Liquid composite molding (LCM) and autoclave. The process selection depends mainly on the size, quality and application of composite. LCM is predominant due to low-cost equipment while the autoclave is used to fabricate CFRP structures for aerospace applications [1]. In the LCM process there are many parameters that influence the quality of composite: resin injection pressure, mould temperature, location of inlet and ventilation gates, application of vacuum, and postcuring [2]. The autoclave process is a high-quality technique to reproduce parts [3]. The laminate quality and curing are related to content, size and distribution of voids in a laminate [4]. The voids and delaminations represent the most common defects due to unsuitable production procedures [5].

In the present work, CFRP and GFRP composites were manufactured, by the two techniques described above, in the National Center for Aeronautical Technologies (CENTA, Querétaro, Mexico) [6]. The composites were cut by diamond saw to analyses the cross section., all samples were imaged in dark field on a Zeiss Axiovert 25 Inverted Microscope, Software Zen lite [7].

As show in Figure 1 a), the composite CFRP manufactured by LCM has some voids with spherical shape, the average size range of 116 to $165 \mu \mathrm{m}$ approximately, there are also other voids with elliptical shape with $1 \mathrm{~mm}$ longitudinal size, and these defects are in the interface between the carbon fiber and the polymer matrix. In the Figure $1 \mathrm{~b}$ ), the same composite manufactured by autoclave technique, showed a good adhesion in the interface between the carbon fibers and the matrix, and there were not voids observed. In the Figure $2 \mathrm{a}$ ) and b) the sectional view GFRP composites manufactured by LCM and autoclave technique, respectively, is showed. Figure 2 a) shows an interface with fiber bundles and in the polymer matrix there were small voids with irregular round shapes an average size range of 10-20 $\mu \mathrm{m}$, approximately. In the Figure $2 \mathrm{~b}$ ), microscopic examination indicated that, there was good adhesion between the matrix and the glass fiber without presence of voids.

The composites that were manufactured by autoclave technique showed an interface polymer-fiber with good adhesion, no voids were found. In CFRP and GFRP composites, by LCM technique, showed interfaces with defects, the CRFP composite showed an interface with voids of different shape and size [7]. 
References:

[1] X Liu and F Chen., Engng. Trans. 64 (2016), p. 33.

[2] C Kaynak and Y Onur Kas, Polymers and Polymer Composites 14 (2006), p. 55.

[3] Lee et al., Composites Science and Technology 166 (2018), p. 150.

[4] Schell et al., Composites Science and Technology 66 (2006), p. 2016.

[5] Di Landro et al., Polymer and Polymer Composites 25 (2017), p. 371.

[6] Vera-Cardenas et al., Micros. and Microanal., 24 (2018), p. 1082.

[7] The authors thank Pablo López-Arriaga and José Reyes-Gasga for the technical support.
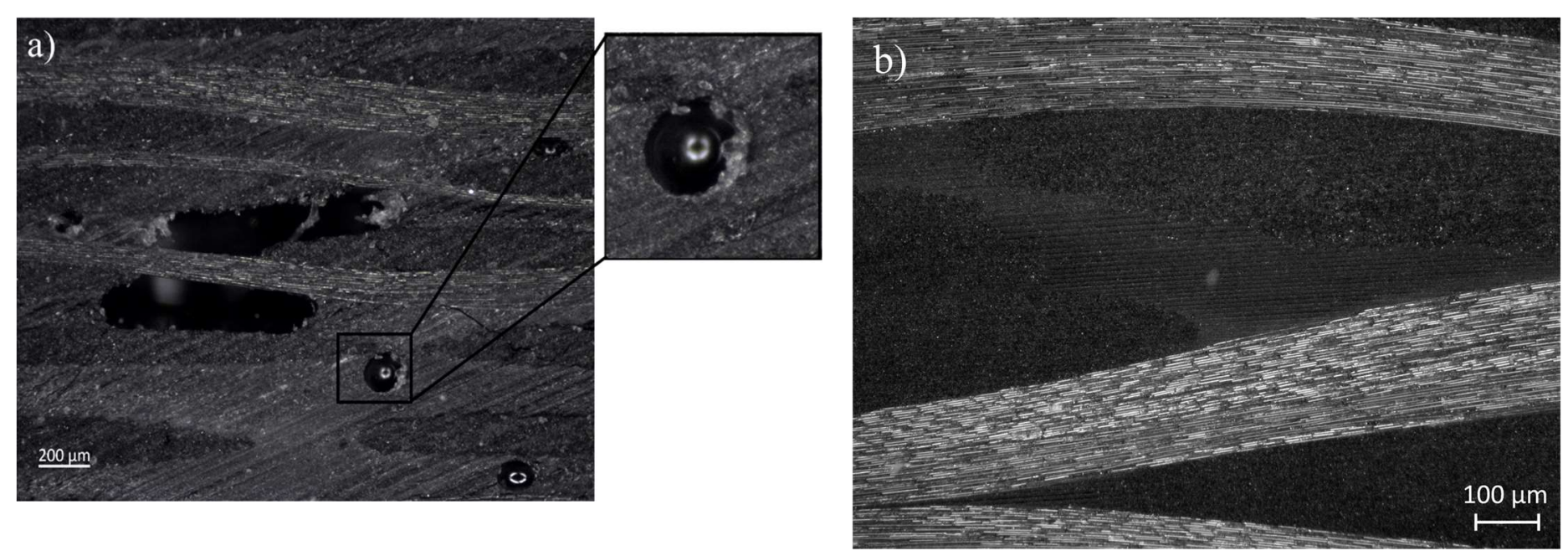

Figure 1. Cross Section of CFRP composites. a) LCD technique, b) autoclave process.
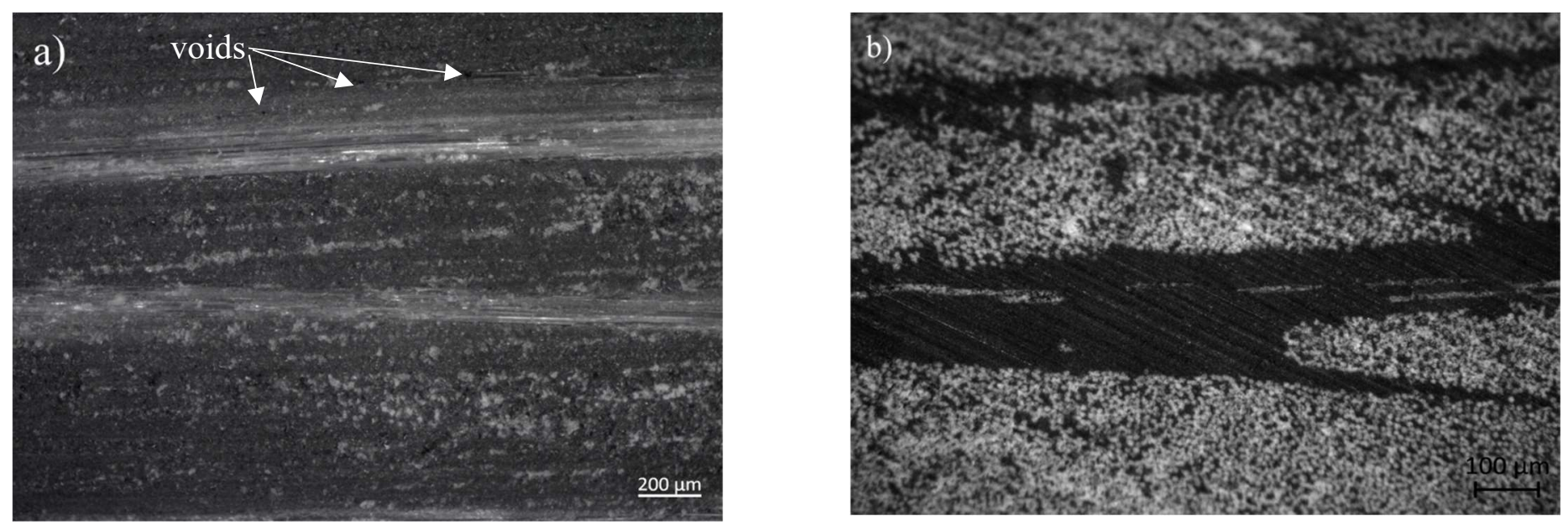

Figure 2. Cross Section of GFRP composites. a) LCD technique, b) autoclave process. 